\title{
Using social media to challenge unwarranted clinical variation in the treatment of chronic noncancer pain: the "Brainman" story
}

This article was published in the following Dove Press journal: Journal of Pain Research

22 September 2016

Number of times this article has been viewed

\section{Ruth White' \\ Chris Hayes' \\ Scott White ${ }^{2}$ \\ Fiona J Hodson'}

'Hunter Integrated Pain Service, Hunter New England Local Health District, Newcastle, NSW, ${ }^{2}$ Hunter New England Central Coast Primary Health Network, Newcastle, NSW, Australia

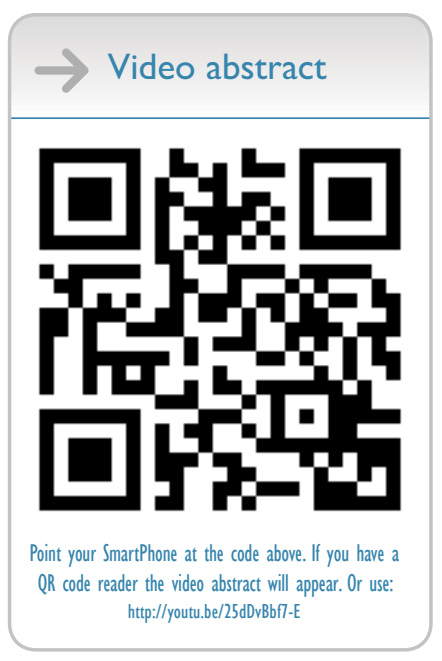

Correspondence: Chris Hayes Hunter Integrated Pain Service, Locked Bag I, Hunter Region Mail Centre, Hunter New England Local Health District, Newcastle, NSW 23I0, Australia $\mathrm{Tel}+6$ I 249223435

Fax +6I 249855045

Email Chris.Hayes@hnehealth.nsw.gov.au
Abstract: There is a substantial clinical variation in the contemporary treatment of chronic noncancer pain reflecting different explanatory models and treatment emphasis. Hunter Integrated Pain Service and collaborators developed three key messaging videos outlining the foundations of chronic pain treatment, thus challenging unwarranted clinical variation and calling for greater therapeutic consistency. The videos were released on YouTube as a low-cost public health intervention. Each video used an evidenced informed script appropriate for low literacy and a cartoonist to provide matching images. The whole-person approach emphasized the role of the nervous system and active self-management approaches over passively received medical treatments. The first video was launched on YouTube in August 2011 and made freely available through a Creative Commons license. Multisource feedback led to refinement of key messages using a broader advisory group. Two further videos were launched on a dedicated YouTube channel in October 2014 and circulated through varied professional and consumer networks. All videos were widely viewed on YouTube, utilized by diverse health care organizations, and independently translated into multiple languages. They were embedded in multiple health-related websites. The first video "Understanding pain in less than 5 minutes" is known to have been translated into 15 languages by other health care organizations. The subsequent two videos (Brainman stops his opioids, and Brainman chooses) were translated into German and subtitled in French and Japanese. When the organization hosting the first video ceased operation in 2015 due to changes in primary health care funding, the video had received $>700,000$ views. Each of the three videos continues to receive $\sim 1,500$ views per month on YouTube. Release of evidence-informed key messages via YouTube is a simple method of challenging clinical variation and providing education about chronic pain across the health care system and community.

Keywords: public health, nervous system, whole-person, YouTube

\section{Introduction}

Unwarranted clinical variation reflects a failure to implement evidenced-based practice. ${ }^{1}$ Such variation is accounted for by the propensity of doctors and other health professionals to offer treatment rather than differences in patient preference or illness. ${ }^{2}$ Warranted clinical variation reflects differences in patient needs at an individual or population level. In addition, a degree of clinical variation is to be encouraged when directed toward practice innovation, provided benchmarking systems are in place to measure potential efficiencies. The ideal health care system has mechanisms in place to limit variation that is not warranted and facilitate variation that is warranted. ${ }^{3}$ 
A degree of clinical variation is to be expected in any evolving area of health care, and the treatment of chronic pain is no exception. Variation occurs in specialist practice, primary care, and the interface between. It relates to differences in both explanatory model and treatment emphasis. Explanatory models, given preeminence by different practitioners, include "pain as a marker of tissue damage" (traditional biomedical approach), "pain as a marker of immutable neural disruption" (disease in the nervous system), and "pain as a lived experience associated with a brain interpretation of threat or danger" (contemporary neuroscience interpretation of the biopsychosocial approach). ${ }^{4}$ Treatment emphasis is strongly influenced by the explanatory model used. Pain as a marker of tissue damage leads to a search for "peripheral drivers" of nociception and pain. Pain as a marker of immutable neural disruption leads to the attempt to downmodulate the nervous system. If either approach fails to bring abolition of pain (as is commonly the case), assistance is offered to live well with ongoing pain. Pain as a lived experience leads to the possibility of modifying the brain interpretation of nociceptive and other inputs to such an extent that the person may come to live well without ongoing pain or at least with significantly reduced pain intensity.

In terms of practical therapeutics, there is substantial clinical variation at the specialist level of pain management. In part, this reflects the type of specialist practice (standalone medical versus multidisciplinary team). However, even within multidisciplinary teams, variation occurs because of the preferences of individual clinicians and their interpretation of the evidence base. In particular, variation is noted in approach to passively received medical treatments such as medicines (including opioids) and procedural interventions (targeted spinal blocks or spinal cord stimulation for example) as compared to active self-management. Some services use such procedural techniques extensively, while others do not use them at all. There is similar variation in practice at the primary care level where some general practitioners commonly prescribe opioid medication to treat chronic pain, whereas others do not. The recently published Australian Atlas of Healthcare Variation has documented a tenfold difference in opioid dispensing across the country. ${ }^{5}$ A major challenge as the field of pain management matures is to reduce clinical variation, and it is here that the concept of key messaging comes to prominence.

A public health, key messaging approach has previously been used in Australia to address clinical variation in the treatment of back pain. The Victorian WorkCover Authority's statewide media campaign "Back pain - don't take it lying down" was launched in 1997 and used prime-time television advertisements featuring health professionals and sports and local television celebrities. ${ }^{6,7}$ The simple messages, all endorsed by the relevant professional health care organizations, included "back pain is not a serious medical problem", "disability can be reduced and even prevented by positive attitudes", and "treatment should consist of continuing to perform usual activities (not resting for prolonged periods), exercising and remaining at work". The campaign successfully modified negative attitudes and beliefs compared to a noninformed population in New South Wales. There was also a decline in the number of workers' compensation back claims and medical payments during the campaign. The changes in beliefs were shown to persist for 3 years. ${ }^{8}$ However, the campaign was expensive and funding was not continued.

Today's availability of social media, that is websites and applications such as Facebook and Twitter that enable users to create and share content (or to participate in social networking), provides an inexpensive and more accessible platform than traditional media. The high uptake of digital technology by health professionals and consumers means social media is ideally suited to communicating health-related messaging quickly to a target audience. YouTube in particular has completely changed the health information landscape, almost rendering traditional print obsolete. A 2012 Price Waterhouse Cooper report on health and social media states: "liking, following, linking, tagging ... is changing the nature of health-related interactions". ${ }^{9}$

In 2011, recognizing the value of partnerships,${ }^{10}$ Hunter Integrated Pain Service (HIPS), a tertiary, public hospital pain clinic located in New South Wales, Australia, collaborated with the not-for-profit primary care organization Hunter Medicare Local (HML) to develop an evidence-informed short video ${ }^{11}$ to explain pain and facilitate a broad approach to active treatment. The primary aim was to make a pain training and educational resource widely available across the primary and tertiary sector of Hunter New England Local Health District. The secondary aim was to provide a resource for people experiencing chronic pain to share with their significant others to gain a better understanding of pain and its management. The HML communications' advice was to aim for distribution via YouTube, making the resource a viable low-cost public health intervention. The messages would address the explanatory model for pain and emphasize treatment options that target areas of known clinical variation. ${ }^{12}$ The low cost of the intervention made a review process achievable, and this permitted the subsequent release of two 
updated videos ${ }^{13,14}$ incorporating feedback received from the first. The project did not have a budget for evaluation; nevertheless, it was hoped that freely sharing the resources via a Creative Commons license on social media would begin to influence pain beliefs in the community and reduce unwarranted clinical variation in the treatment of chronic noncancer pain across the health care system.

\section{Methods}

In the world of social media, expert practitioners declare that "content is king". In order to begin the process of content development, clinicians at HIPS were asked to write their own key messages about chronic pain using ten words or less. This task of synthesizing brief evidence-based messages into a short script contrasted sharply to the more familiar and expansive writing styles of scientific literature.

The next step involved refining and prioritizing the key messages through team-based discussion. The purpose was to inform clinical practice by addressing explanatory model and treatment emphasis. The explanatory model of "pain as a lived experience associated with a brain interpretation of threat or danger" was chosen as being the best reflection of existing evidence. The associated treatment emphasis endorsed the greater capacity of active self-management, as compared to passively received medical treatments, to bring therapeutic benefit.

In addition to brevity, it was also recognized that messages needed to be delivered at an appropriate level of literacy. Low literacy and low health literacy are common among people presenting to specialist pain management services. Data available from benchmarking of pain services across Australia and New Zealand showed that $15.2 \%$ of patients presenting to HIPS acknowledged the need for assistance with completion of an entry questionnaire. This compared to $12.5 \%$ for the all services average. ${ }^{15}$

Following finalization of the script, a professional media company and artist commenced initial drawings, ${ }^{16}$ and extensive liaison occurred to ensure that appropriate pictures were utilized to illustrate key messages. Simple cartoon style pictures were chosen to convey the content clearly. ${ }^{17}$ It was possible to incorporate clinical complexity into the drawings, for example, a drawing representing the cartoon figure returning to work while still experiencing pain was utilized.

The importance of repetition of key messages was also recognized, and this was a particular focus in the second and third videos. ${ }^{18,19}$ A professional voice artist read the scripts in all three videos. ${ }^{11,13,14}$
The first video ${ }^{11}$ (Understanding pain in less than 5 minutes) produced in 2011 focused on delivering the key message, explaining "all pain is produced by the brain". This was supported by reference to "a brain that keeps on producing pain after body tissues are out of danger". A cartoon picture of a brain and nervous system was created to highlight the central role of the nervous system in the explanatory model of pain; "Brainman" was born (Figure 1).

In terms of treatment emphasis, a hand with five fingers was chosen as a pictorial means of conveying a broad or whole-person approach and limiting the video to five therapeutic messages (Figure 2). It was felt that this was an interpretation of the biopsychosocial model that would be easily understood by "lay" people. ${ }^{20}$ The five fingers represented medical treatment, thoughts and emotions, diet and lifestyle, personal story, and physical activity. The overarching treatment message was that "once dangerous conditions are ruled out" (red flags), making positive changes in any of the five key areas had the potential to "retrain the brain and nervous system" and reduce pain over time.

Medical treatments were represented by the thumb. It was recognized that they had a limited place compared to the active treatments represented by the remaining four fingers, which had greater capacity to "retrain the brain and nervous system". The importance of ruling out red flag conditions was emphasized prior to progression to active self-management. Time-limited medication use (wean and cease) and caution with respect to surgery were recommended.

The second finger represented thoughts and emotions acknowledging that these play an important role in the experience of pain. The message "thoughts and emotions are brain impulses too" was used to promote the concept that addressing this aspect could calm the nervous system

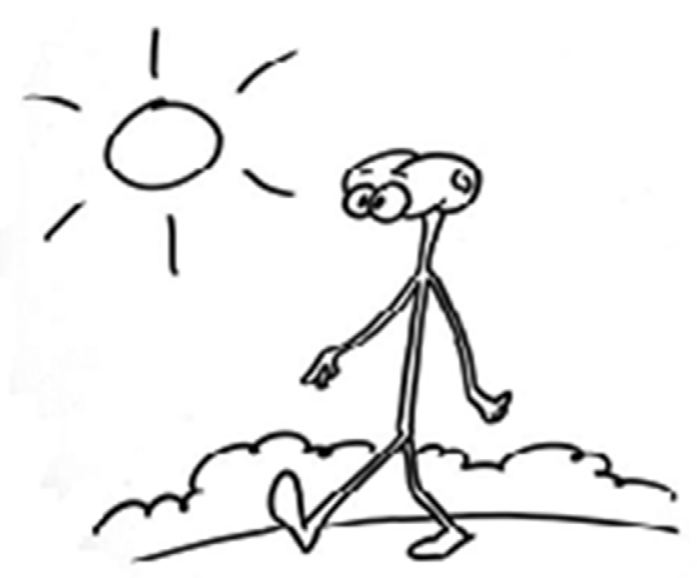

Figure I Brainman. 


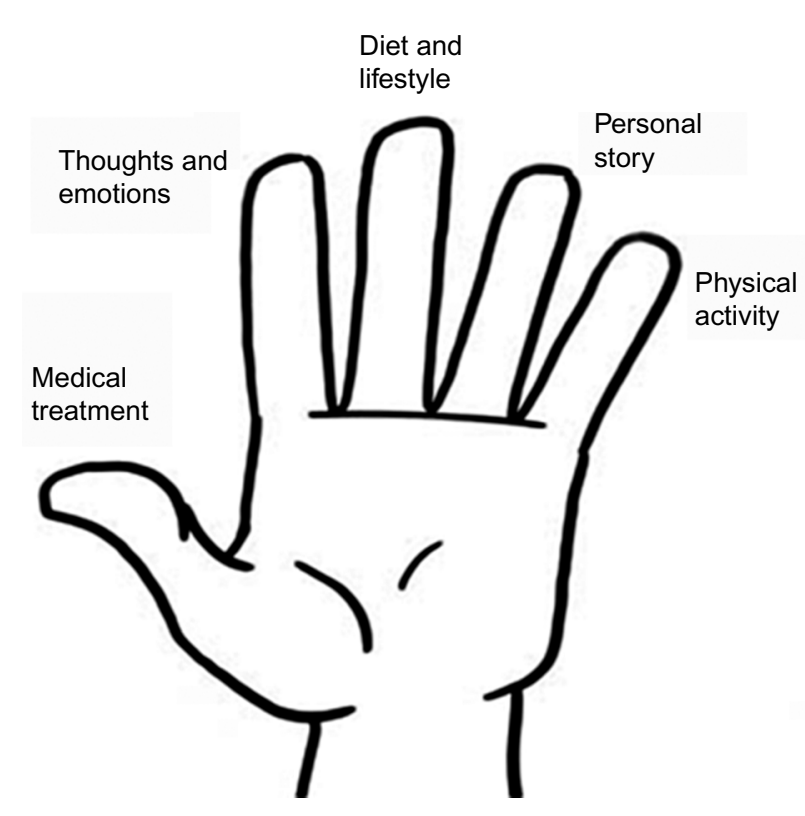

Figure 2 Whole-person approach Version I.

and reduce the experience of pain. The third finger represented diet and lifestyle factors, ${ }^{21,22}$ which were also framed as potentially influencing the brain and nervous system and hence the experience of pain. The fourth finger represented personal story and was used to introduce a psychodynamic perspective ${ }^{23,24}$ and the common links between "a worrying period of life and a worsening pain picture". It was noted that the "recognition of deeper emotions can be part of the healing process". The fifth finger represented physical activity. "Moving without fear" so that "the brain does not protect by pain" was encouraged. This recognized the important role of activity not only in restoring musculoskeletal tissues but also in retraining the brain and nervous system..$^{25,26}$

In 2014 , content was refined to develop two updated videos $^{13,14}$ based on consumer and health professionals' feedback. The original team remained involved, and input from a broader clinical advisory group was sought. Colleagues from the University of South Australia and the University of Washington, National Institutes of Health Pain Consortium, were added based on the interest shown in the first video. ${ }^{11}$ It was also agreed that the University of South Australia would undertake research to investigate the power of the videos to influence the behavior of health professionals.

The recommendation of the advisory group was to make the subsequent videos shorter and with more repetition. It was agreed that the 2011 video, ${ }^{11}$ which had deliberately been kept under 5 minutes, was too long for busy general practitioners with time-limited consultations. ${ }^{27}$ Hence, "Brainman stops his opioids" was restricted to 1 minute 30 seconds and "Brainman chooses" to 2 minutes 30 seconds.
Opioid weaning and the transition to active self-management were selected as key behavior change targets for both health professionals and patients. An entire video "Brainman stops his opioids"13 was devoted to opioid deprescribing in recognition of the extent of clinical variation in that area. The "Brainman chooses" $" 14$ video updated active self-management options and used the repeated metaphor of "changing knowledge" represented as bricks in the wall. ${ }^{28}$

The key message from "Brainman stops his opioids" was that "opioids are no longer recommended for chronic noncancer pain". This was based on lack of efficacy ${ }^{29}$ ("most people taking opioids experience early gains but it does not last"13) and risk of adverse effects ${ }^{30}$ ("people taking opioids often develop other problems"13).

In "Brainman chooses", the updated "whole-person" approach used a realigned five fingers, this time representing biomedical, mindbody, connection, activity, and nutrition (Figure 3). From a literacy perspective, one word was chosen for each finger. "Biomedical" was used to cover medical treatments. "Mindbody" was used to represent both the "thoughts and emotions" and "personal story" aspects of Version 1. This allowed for a "connection" finger to emphasize the social and environmental aspects lacking in the early version. "Activity" retained a place. "Nutrition" was selected as a simplification of "diet and lifestyle", recognizing that all the fingers incorporated aspects of lifestyle. In addition, sleep was chosen as an important area that had not been highlighted in the first video. ${ }^{11}$ It was addressed under the "activity" finger.

The initial video was launched in August 2011 and cost AUS\$12,500. It was funded solely by HML with HIPS providing in kind contribution to the content. The launch was substantially via the national and international pain communities and word of mouth. The subsequent two videos ${ }^{13,14}$ were launched

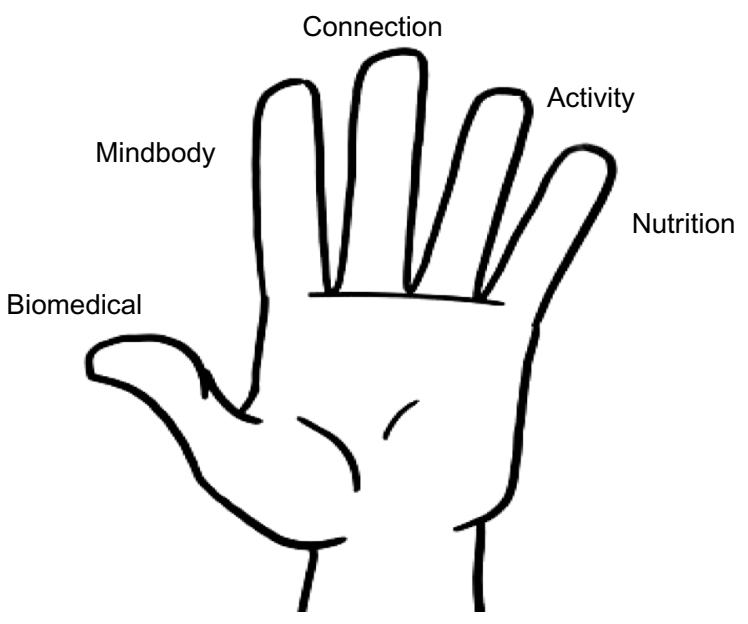

Figure 3 Whole-person approach Version 2. 
in October 2014 with a total combined cost of AUS $\$ 8,000$ shared equally between HML and HIPS. A dedicated YouTube channel was created for this second launch. ${ }^{31}$ A Facebook site was also created by the authors. The launch was again publicized via the pain community, including consumer organizations and those who had previously expressed interest. The second launch coincided with the 15th World Congress on Pain in Buenos Aires, Argentina. Brainman was informally publicized by word of mouth at that event.

No dedicated funding was available for evaluation. However, the email network developed for the launches facilitated extensive feedback to the authors.

\section{Results}

Tracking the number of views on YouTube is one measure of the impact of the Brainman videos. The view count and distribution of the top 30 countries are shown for the first 3 months after launch of the initial video in Figure 4. Further analysis by age group and sex for the top ten countries is shown in Figure 5. During the same time period, smaller numbers of views $(<50)$ across an additional 80 countries demonstrated the wide geographical extent of interest (Table 1). Unfortunately, the largest record of these views $(>700,000)$ was lost in 2015 when the HML YouTube channel was taken down when that organization ceased operation. The YouTube view count was also complicated by the fact that the videos were also separately hosted by other professional and consumer organizations on their own websites. Thus, a comprehensive view count was not possible. However, it would be reasonable to make a conservative estimate that the combined total viewings of the Brainman series have exceeded 1 million views on YouTube. Each video continues to receive 1,500 views per month via the dedicated Brainman YouTube channel.

Another measure of the impact of the Brainman series was the extensive email network that developed and the widespread sharing of the videos. Up until the end of 2014, HIPS was contacted by $>400$ health care or consumer organizations offering feedback or requesting permission to share the YouTube links or use copies of the videos, for example, on their own websites or in group programs, clinic waiting rooms, and teaching programs. Those requesting permission to use the videos included $>200$ contacts from Australia, 19 from the USA, 19 from the UK, nine from New Zealand, eight from Canada, and five from mainland Europe. The consumer organizations involved were Pain Australia, Australian Pain Management Association, Chronic Pain Australia and Pete Moore's Pain Tool Kit, and the Pain Association of Scotland in the UK. The prominent professional organizations in Australia included the Australian Pain Society; National Prescribing Service; Pain Management and Research Institute, University of Sydney; BodyinMind; Noigroup; Rural Health Education Foundation; Agency for Clinical Innovation, New South

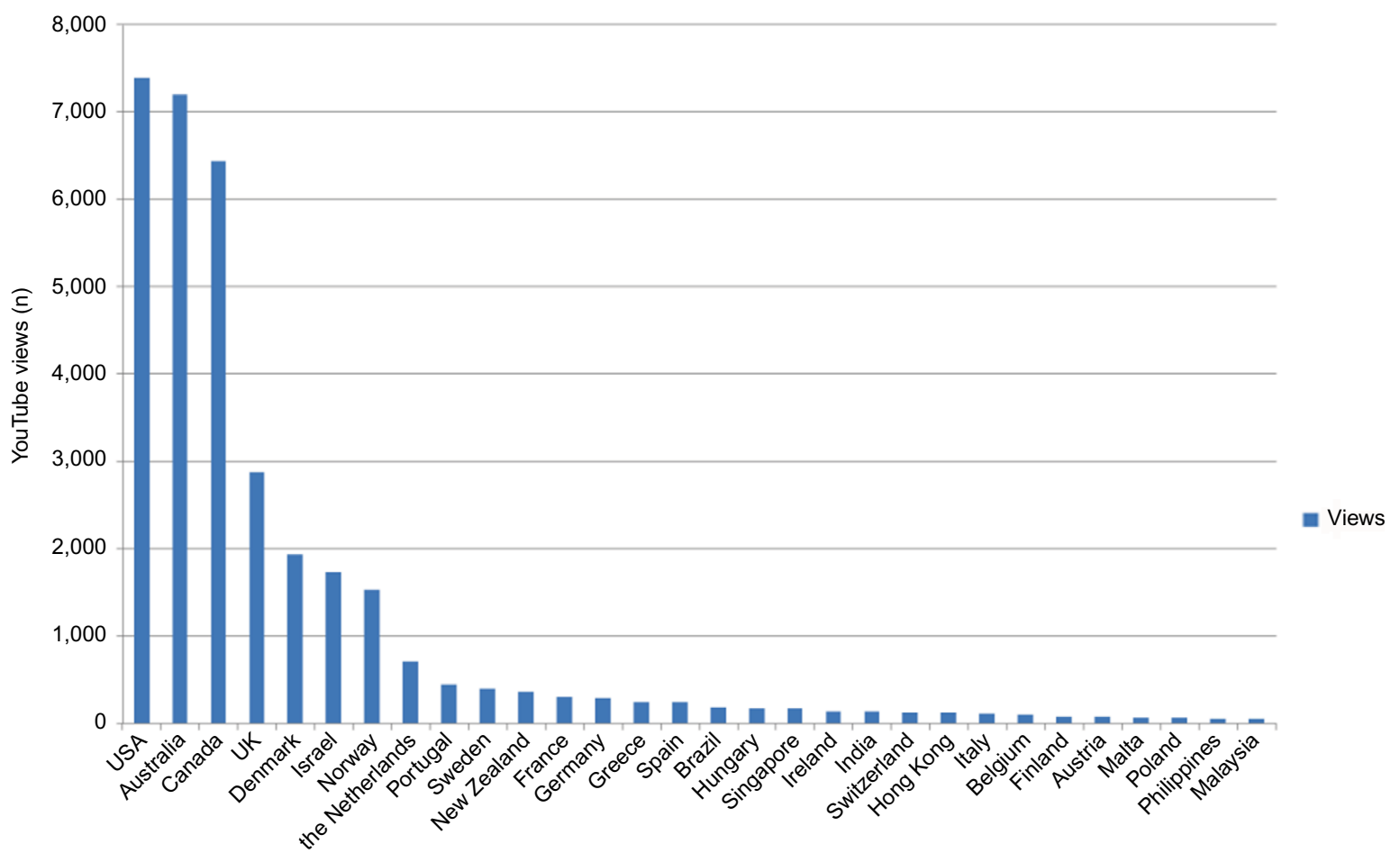

Figure 4 YouTube/Google analytics for Video"l "Understanding pain in less than five minutes”: view count of top 30 countries (August 30, 20 I I-December 4, 20I I). 


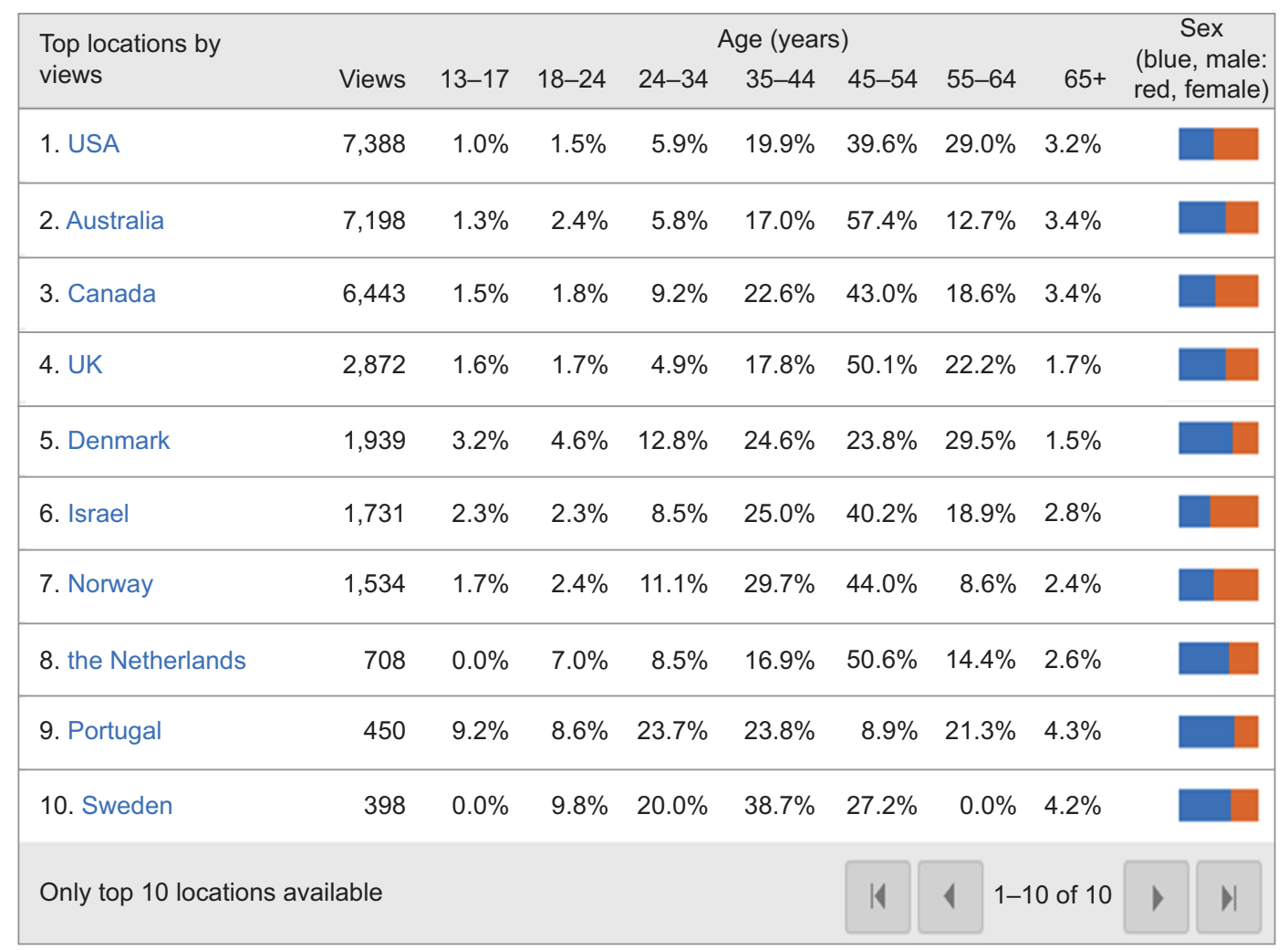

Figure 5 YouTube/Google analytics for Video" "Understanding pain in less than five minutes”: view count by age and sex (August 30, 20II-December 4, 20II).

Table I YouTube/Google analytics for Video" "Understanding pain in less than five minutes": countries with <50 views (August 30, 20II-December 4, 20II)

\begin{tabular}{|c|c|c|c|c|c|}
\hline North America & South America & Africa & Asia & Europe & Oceania \\
\hline Bahamas & Argentina & Algeria & Afghanistan & Albania & French Polynesia \\
\hline Bermuda & Bolivia & Angola & Armenia & Bulgaria & Guam \\
\hline Cayman Islands & Chile & Egypt & Bahrain & Croatia & Norfolk Island \\
\hline Costa Rica & Columbia & Ghana & Georgia & Cyprus & \\
\hline Dominican Republic & Peru & Kenya & Indonesia & Czech Republic & \\
\hline El Salvador & Trinidad and Tobago & Mauritius & Iraq & Estonia & \\
\hline Guadeloupe & Uruguay & Morocco & Japan & Gibraltar & \\
\hline Guatemala & Venezuela & Nigeria & Jordan & Greenland & \\
\hline Mexico & & Reunion Island & Kazakhstan & Guernsey & \\
\hline \multirow[t]{16}{*}{ Puerto Rico } & & Rwanda & Kuwait & Iceland & \\
\hline & & South Africa & Laos & Isle of Man & \\
\hline & & Tunisia & Lebanon & Latvia & \\
\hline & & Uganda & Nepal & Lithuania & \\
\hline & & Zimbabwe & Pakistan & Luxembourg & \\
\hline & & & Qatar & Moldova & \\
\hline & & & Russia & Romania & \\
\hline & & & Saudi Arabia & Serbia & \\
\hline & & & South Korea & Slovenia & \\
\hline & & & Sri Lanka & Ukraine & \\
\hline & & & Taiwan & & \\
\hline & & & Thailand & & \\
\hline & & & Turkey & & \\
\hline & & & United Arab Emirates & & \\
\hline & & & Vietnam & & \\
\hline & & & Yemen & & \\
\hline
\end{tabular}


Wales; NSW Therapeutic Advisory Group; and NSW State Insurance Regulatory Authority. The noteworthy overseas professional organizations included the Department of Veterans Affairs and Department of Defense, USA; Cleveland Clinic and Mayo Clinic, USA; Calgary Chronic Pain Program and Calgary Foothills Primary Care Network, University of Calgary, Canada; and Healthcare Improvement Scotland. There were several requests from areas of niche application. These included prison systems (Arthur Gorrie Correctional Centre in Australia and Washington State Penitentiary in the USA) and pediatric, geriatric, and spinal cord injury services.

Additional evidence of the impact of the Brainman videos was the translation into multiple languages by health professional and consumer organizations. The initial video was known to have been translated into Arabic, Cantonese, Danish, French, German, Greek, Hebrew, Italian, Japanese, Mandarin, Norwegian, Portuguese, Spanish, Swedish, and Vietnamese. It was also subtitled in English for the hearing impaired. The subsequent two videos ("Brainman stops his opioids" and "Brainman chooses") $)^{13,14}$ were translated into German and subtitled in French and Japanese. Beyond the exercise of translation, a number of organizations further modified Brainman content including script and drawings to better target local needs. Examples of such content modification included the development of an "Americanized" version of Brainman by the Department of Defense and Department of Veterans Affairs under the auspices of the Joint Pain Education Program. ${ }^{32}$ Pain clinic staff at Providence Health \& Services in OR, USA, also reworked script and images and included a patient story. A group from Denmark developed a poster based on the Brainman content.

Prior to the October 2014 launch, colleagues from the University of South Australia explored the potential for the two new Brainman videos to bring behavioral change. The outcomes of this research will be reported elsewhere.

\section{Discussion}

The novel intervention of developing evidence-informed key messages for launch via YouTube began as a one-off project for staff at HIPS in collaboration with HML. The intention was to make a pain resource available for sharing locally, and there was no anticipation that the project would attract global attention. The writing team was surprised by the level of interest shown in the first video both nationally and internationally. This encouraged a more strategic approach to the development of the subsequent two videos. Collaboration with a broader advisory group was beneficial in refining the messages and publicizing the second launch.
Reflecting upon the widespread interest in the Brainman series, the authors reaffirmed the view that in the world of social media, content is king. The development of short, high-quality videos combined with the YouTube platform was fundamental to Brainman's success.

The full impact of the Brainman video series was difficult to quantify, particularly in view of the lack of budget for evaluation. The YouTube view count provided one measure of impact; however, this was unsatisfactory as a sole measure because the original launch channel was taken down and because multiple organizations hosted the videos on their own websites or embedded copies of the videos in their own educational material. Hence, the number of influential health professional and consumer organizations that engaged with Brainman is relevant in providing a more complete assessment of impact. The way in which multiple organizations went beyond simply sharing the Brainman videos and undertook translation or modification of script or images appropriate for their context was particularly noteworthy. The investment of time and effort required for such modification projects was a further measure of the regard with which the original content material was held.

There was a limited amount of negative comments from medical practitioners with a focus on interventional procedures. In their opinion, there was a lack of support expressed for the importance of such interventions. There were also some negative comments from patients prescribed chronic opioid therapy. The project team elected not to respond to any online comments, positive or negative, and this YouTube function was disabled.

The strengths of the current study included the novel methodology in utilizing social media to deliver consistent key messages for people experiencing chronic noncancer pain. The resources that were developed were of low cost and could be shared freely. The use of Creative Commons license facilitated this process and allowed widespread dissemination and translation into many languages and across different cultures. The resources were of interest to health professionals working in diverse settings in primary and specialist care and in unidiscipline practices and multidisciplinary teams.

One limitation of this work was the lack of formal evaluation process stemming from the lack of funding. However, this is a common limiting factor in the public health system. Another limitation related to the challenges of using the YouTube platform. There was a lack of continuity of host channels and hence breakage of Internet links. Furthermore, many Australian hospitals block access to YouTube for staff when using hospital computing systems. This limitation was 
partially overcome as various organizations contacted HIPS and obtained their own copies of the videos. In addition, the videos were made available as free downloadable files on the HIPS website. ${ }^{33}$

The intention behind developing the Brainman series was to challenge unwarranted clinical variation and to call for a more consistent approach to the treatment of chronic noncancer pain. At the same time, it was recognized that the videos were only one small offering in the complex global field of health. In the Australian context, it was interesting to note that several key health care organizations updated their recommendations about opioid use in chronic noncancer pain in 2015 to incorporate a greater emphasis on the possibility of opioid deprescribing. These organizations included the Faculty of Pain Medicine, the National Prescribing Service, the NSW Therapeutic Advisory Group, and the NSW Agency for Clinical Innovation. These recommendations all provided a link to the Brainman videos or referenced source documentation on the HIPS website. ${ }^{34} \mathrm{On}$ this basis, it is possible that the Brainman series played a part in furthering the debate about prescribing opioids in Australia. There has also been a considerable debate in Australia about the therapeutic alternatives to opioid prescribing for chronic noncancer pain. "Brainman chooses" has often been recommended in this context as it endorses active self-management as a possible alternative approach.

\section{Conclusion}

Release of evidence-informed key messages via YouTube and other social media applications is a simple method of delivering a collaborative, low-cost public health intervention. The Brainman video series continues to challenge clinical variation and provides education about chronic pain across the health care system and wider community.

\section{Disclosure}

Chris Hayes is a pain medicine physician and director of Hunter Integrated Pain Service (HIPS). Ruth White (pain management physiotherapist) and Fiona J Hodson (clinical nurse consultant) are also part of the HIPS team. HIPS is a copyright owner of the Brainman video series under Creative Commons license. Scott White was previously communications manager of Hunter Medicare Local (HML) prior to the organizations closure. HML was also a copyright owner of the Brainman video series. Funding for the video series was supplied by HML and HIPS.

\section{References}

1. Wennberg JE. Unwarranted variations in healthcare delivery: implications for academic medical centres. BMJ. 2002;325:961-964.
2. Wennberg JE. Time to tackle unwarranted variations in practice. $B M J$. 2011;342:d1513.

3. Mulley AJ. Improving productivity in the NHS. BMJ. 2010;341:c3965.

4. Moseley GL, Butler DS. 15 years of explaining pain - the past, present and future. J Pain. 2015;16(9):807-813.

5. Australian Commission on Safety and Quality in Health Care and National Health Performance Authority. Australian Atlas of Healthcare Variation. Sydney: ACSQHC; 2015.

6. Buchbinder R, Jolley D, Wyatt M. Population based intervention to change back pain beliefs and disability: three part evaluation. BMJ. 2001;322:1516-1520.

7. Buchbinder R, Jolley D, Wyatt M. Effects of a media campaign on back pain beliefs and its potential influence on management of low back pain in general practice. Spine. 2001;26(23):2535-2542.

8. Buchbinder R, Jolley D. Effects of a media campaign on back beliefs is sustained 3 years after its cessation. Spine. 2005;30(11):1323-1330.

9. PricewaterhouseCooper's Health Research Institute (HRI). Social Media "Likes" Healthcare: From Marketing to Social Business. USA: Health Research Institute; 2012.

10. Krist AH, Woolf SH, Rothemich SF, Johnson RE, Wilson DB. It takes a partnership: the value of collaboration in developing and promoting a web site for primary care patients. Ann Fam Med. 2005;3(suppl 2):S47-S49.

11. Understanding pain in less than five minutes. Video on YouTube. October 2, 2014. Available from https://m.youtube.com/watch? $\mathrm{v}=5 \mathrm{KrUL} 8 \mathrm{tOaQs}$. Accessed August 30, 2016.

12. Valjakka AL, Salanterä S, Laitila A, Julkunen J, Hagelberg NM. The association between physicians' attitudes to psychosocial aspects of low back pain and reported clinical behaviour: a complex issue. Scand J Pain. 2013;4(1):25-30.

13. Understanding pain: Brainman stops his opioids. Video on YouTube. October 3, 2014. Available from https://m.youtube.com/ watch?v=MI1myFQPdCE. Accessed August 30, 2016.

14. Understanding pain: Brainman chooses. Video on YouTube. October 3 , 2014. https://m.youtube.com/watch? $\mathrm{v}=\mathrm{jIwn} 9 \mathrm{rC} 3 \mathrm{rOI}$. Accessed August 30, 2016.

15. Electronic Persistent Pain Outcomes Collaboration [webpage on the Internet]. Pain Management Services Report; 2014. Available from: http://ahsri.uow.edu.au/content/groups/public/@web/@chsd/@aroc/ documents/doc/uow189431.pdf. Accessed July 15, 2016.

16. Pratt K [webpage on the Internet]. SilverSun Pictures; 2011. Available from: http://silversunpictures.com.au/about/. Accessed August 12, 2016.

17. Houts PS, Doak CC, Doak LG, Loscalzo MJ. The role of pictures in improving health communication: a review of research on attention, comprehension, recall, and adherence. Patient Educ Couns. 2006; 61(2):173-190.

18. Berkman ND, Sheridan SL, Donahue KE, et al. Health Literacy Interventions and Outcomes: an Updated Systematic Review. Evid Rep Technol Assess (Full Rep). 2011:199;1-941.

19. Main CJ, Buchbinder R, Porcheret M, Foster N. Addressing patient beliefs and expectations in the consultation. Best Pract Res Clin Rheumatol. 2010;24(2-2):219-225.

20. Wilson EA, Wolf MS. Working memory and the design of health materials: a cognitive factors perspective. Patient Educ Couns. 2009;74(3):318-322.

21. Hayes C, Naylor R, Egger G. Understanding chronic pain in a lifestyle context: the emergence of a whole person approach. Am J Lifestyle Med. 2012;6(5):421-429.

22. Naylor R, Hayes C, Egger G. The relationship between lifestyle, metaflammation and chronic pain: a systematic review. Am J Lifestyle Med. 2013;7(2):130-137.

23. Broom B. Somatic Illness and the patient's Other Story. A Practical Integrative Mind/Body Approach to Physical Illness. London: Free Association Books; 1997.

24. Broom B. Meaning-Full Disease. London: Karnac Books; 2007.

25. Sluka KA, O'Donnell JM, Danielson J, Rasmussen LA. Regular physical activity prevents development of chronic pain and activation of central neurons. J Appl Physiol. 2013;114:725-733. 
26. Ellingson LD, Shields MR, Stegner AJ, Cook DB. Physical activity, sustained sedentary behavior and pain modulation in women with fibromyalgia. J Pain. 2012;13:195-206.

27. Britt H, Valenti L, Miller G. Time for care. length of general practice consultations in Australia. Aust Fam Physician. 2002;31(9): 876-880.

28. Altman DG. Building a metaphor: another brick in the wall? BMJ. 2012; 345:e8302.

29. Ballantyne JC, Shin NS. Efficacy of opioids for chronic pain: a review of the evidence. Clin J Pain. 2008;24(6):469-478.

30. Provenzano DA, Viscusi ER. Rethinking the role of opioids in the outpatient management of chronic nonmalignant pain. Curr Med Res Opin. 2014;30(10):2051-2062.
31. HunterBrainman [webpage on the Internet]. Available from: https:// www.youtube.com/user/HunterBrainman. Accessed July 15, 2016.

32. Defense \& Veterans Center for Integrative Pain Management [webpage on the Internet]. Joint Pain Education Project (JPEP). Available from: http://www.dvcipm.org/clinical-resources/joint-pain-education-projectjpep. Accessed July 15, 2016.

33. Hunter Integrated Pain Service [webpage on the Internet]. "Brainman Videos," Educational Videos. Available from: http:/www.hnehealth.nsw. gov.au/Pain/Pages/Educational-videos.aspx. Accessed July 15, 2016.

34. Hunter Integrated Pain Service [webpage on the Internet]. Reconsidering Opioid Therapy - A Hunter New England Perspective. Available from: http://www.hnehealth.nsw.gov.au/Pain/Documents/Reconsidering_opioid_therapy_May\%202014.pdf. Accessed July 15, 2016.
Journal of Pain Research

\section{Publish your work in this journal}

The Journal of Pain Research is an international, peer reviewed, open access, online journal that welcomes laboratory and clinical findings in the fields of pain research and the prevention and management of pain. Original research, reviews, symposium reports, hypothesis formation and commentaries are all considered for publication.

\section{Dovepress}

The manuscript management system is completely online and includes a very quick and fair peer-review system, which is all easy to use. Visit http://www.dovepress.com/testimonials.php to read real quotes from published authors. 